\title{
Downregulation of Otospiralin, a Novel Inner Ear Protein, Causes Hair Cell Degeneration and Deafness
}

\author{
Benjamin Delprat, ${ }^{1 *}$ Ana Boulanger, ${ }^{1 *}$ Jing Wang, ${ }^{1}$ Vicky Beaudoin, ${ }^{2}$ Matthieu J. Guitton, ${ }^{1}$ Stéphanie Ventéo, ${ }^{3}$ \\ Claude J. Dechesne, ${ }^{3}$ Rémy Pujol, ${ }^{1}$ Mireille Lavigne-Rebillard, ${ }^{1}$ Jean-Luc Puel, ${ }^{1}$ and Christian P. Hamel ${ }^{1}$ \\ 1/nstitut National de la Santé et de la Recherche Médicale U. 254, Laboratoire de Neurobiologie de l'Audition, 34090 \\ Montpellier, France, '2Département de Chimie-Biologie, Université du Québec à Trois-Rivières, Trois-Rivières (Québec), \\ Canada, G9A 5H7, and 3/nstitut National de la Santé et de la Recherche Médicale U. 432, Neurobiologie et \\ Développement du Système Audiovestibulaire, Université Montpellier II, 34095 Montpellier cedex 05, France
}

\begin{abstract}
Mesenchymal nonsensory regions of the inner ear are important structures surrounding the neurosensory epithelium that are believed to participate in the ionic homeostasis of the cochlea and vestibule. We report here the discovery of otospiralin, an inner ear-specific protein that is produced by fibrocytes from these regions, including the spiral ligament and spiral limbus in the cochlea and the maculae and semicircular canals in the vestibule. Otospiralin is a novel $6.4 \mathrm{kDa}$ protein of unknown function that shares a protein motif with the gag p30 core shell nucleocapsid protein of type $\mathrm{C}$ retroviruses. To evaluate its
\end{abstract}

functional importance, we downregulated otospiralin by cochlear perfusion of antisense oligonucleotides in guinea pigs. This led to a rapid threshold elevation of the compound action potentials and irreversible deafness. Cochlear examination by transmission electron microscopy revealed hair cell loss and degeneration of the organ of Corti. This demonstrates that otospiralin is essential for the survival of the neurosensory epithelium.

Key words: otospiralin; cochlea; vestibule; hair cell; deafness; gene; antisense; inner ear
In the mammalian inner ear, proper functioning of hair cells depends on the ionic composition of endolymph and perilymph. Structures that participate in the ionic balance are the stria vascularis in the cochlea and the dark cells in the vestibule that produce the potassium-rich endolymph, but also mesenchymal nonsensory regions, i.e., the spiral limbus proximal to the cochlear axis and the spiral ligament behind the stria vascularis in the cochlea and the stroma lying beneath the sensory epithelium in the vestibule. Indeed, the fibrocytes from these regions express Na,K-ATPase, and carbonic anhydrases II and III (Spicer et al., 1990, 1997; Spicer and Schulte, 1991) as well as various channels and transporters (Stankovic et al., 1995; Sakaguchi et al., 1998; Couloigner et al., 2001), extracellular matrix proteins (Tsuprun and Santi, 1999; Weinberger et al., 1999; Mothe and Brown, 2001), and regulatory molecules (Thomadakis et al., 1999). The finding that some fibrocytes also express gap junction connexins 26, 30, and 31 (Lautermann et al., 1998; Kikuchi et al., 2000; Xia et al., 2000) and the chloride-iodide transporter pendrin (Everett et al., 1999; Scott et al., 1999) is a further indication of their importance in the fluid movements in the inner ear. These fibro-

Received Sept. 19, 2001; revised Dec. 10, 2001; accepted Dec. 10, 2001.

B.D. has a fellowship from Caisse d'Epargne, Montpellier and Région Languedoc-Roussillon, France. We are grateful to G. Rebillard and E. Wilcox for providing cDNA libraries. We thank N. Daudet, M. Eybalin, M. Gallego, G. Humbert, and N. Renard for immunohistochemistry, C. Gervais d'Aldin and J. Ruel for their help in physiological studies, and J.-L. Pasquier for art work.

Correspondence should be addressed to Christian P Hamel, Institut National de la Santé et de la Recherche Médicale U. 254, 71 rue de Navacelles, 34090 Montpellier, France, E-mail: hamel@montp.inserm.fr., or Jean-Luc Puel, same address, E-mail: puel@montp.inserm.fr.

*B.D. and A.B. contributed equally to this work

A. Boulanger's present address: Laboratory of Retinal Cell and Molecular Biology, Building 6, Room 339, National Eye Institute/National Institutes of Health, 6 Center Drive, MSC 2740, Bethesda, MD 20892-2740.

Copyright (C) 2002 Society for Neuroscience $\quad 0270-6474 / 02 / 221718-08 \$ 15.00 / 0$ cytes are a heterogenous cell population, classified in the spiral ligament as types I-V on the basis of their location and marker expression, suggesting a certain level of diversity in the ion homeostasis function.

Recently, the search for preferentially expressed inner ear mRNAs has led to the discovery of novel proteins expressed in the mesenchymal regions. Fdp/otoraplin is a secreted polypeptide related to a cartilage-derived protein expressed in all types of fibrocytes from the spiral ligament, spiral limbus, and mesenchymal cells underlying the basilar membrane (Cohen-Salmon et al., 2000; Robertson et al., 2000; Rendtorff et al., 2001). Otoraplin could initiate the induction of chondrogenesis in the cochlea during development (Cohen-Salmon et al., 2000). Cochlin is also a secreted protein of unknown function found in the same regions as otoraplin in the cochlea and in the stroma underlying the sensory epithelium in the vestibule (Robertson et al., 1998). Both proteins may participate in structural or regulatory functions in the inner ear, thus suggesting more diversity and complexity of the mesenchymal tissues than envisioned previously.

By systematic sequencing of rat cochlea cDNA libraries, we identified several genes preferentially expressed in cochlea and outer hair cells (Soto-Prior et al., 1997; Harter et al., 1999). One of these genes was selected for its inner ear-specific expression. We report here that it encodes otospiralin, a novel protein found in fibrocytes of spiral limbus, spiral ligament, and subepithelial regions of the vestibule. Otospiralin shares a protein motif with the gag p30 core shell nucleocapsid protein of type $C$ retroviruses. In the guinea pig, transient downregulation of otospiralin by use of antisense oligonucleotides leads to vestibular dysf unction and irreversible deafness. Cochlear electrophysiology and transmission electron microscopy analysis indicate that hair cells were degenerating in these deaf animals. 


\section{MATERIALS AND METHODS}

\section{$D N A$ isolation and sequencing}

pCO8, an incomplete cDNA clone from rat otospiralin, was found by systematic sequencing (Soto-Prior et al., 1997). To obtain the $5^{\prime}$ end of the rat otospiralin mRNA, we screened by PCR a cDNA phage library (G. Rebillard, unpublished results) using vector primers and a specific primer from the $5^{\prime}$ end of the pCO 8 cDNA (Soto-Prior et al., 1997). The resulting cDNA fragment was cloned into pBluescript $\mathrm{SK}(+)$. For human and mouse otospiralin mRNAs, we PCR-amplified a $1.2 \mathrm{~kb}$-long fragment from genomic DNA using forward hgSG6S1 5'-ATGCAGCCCTGTCTGCTGTGGTGG-3' and reverse hgSG6AS15' -GTCCTCCTGGTAGGGAACATGGAA-3' primers from both ends of the rat open reading frame and deduced the cDNAs by comparison with the rat sequence. For the guinea pig otospiralin mRNA, we PCR-amplified a 160 bp-long cDNA from genomic DNA in the 3' region conserved among otospiralin orthologs with the forward hgSG6S2 5'-CATGCCTTACTGGCCTTTTTCCACCTCTGA-3' and reverse hgSG6AS1 primers. This cDNA was digoxigenin labeled (DIG High Prime Labeling and Detection Kit, Boehringer Mannheim, Mannheim, Germany) and hybridized overnight at $68^{\circ} \mathrm{C}$ to membrane replicates of a guinea pig organ of Corti library (Wilcox and Fex, 1992). Positive colonies were then amplified, and plasmids were isolated. Rat and guinea pig cDNA clones and mouse genomic fragments were sequenced using the PRISM Ready Reaction Big dye terminator cycle sequencing kit on an ABI 310 DNA Sequencer (PerkinElmer Life Sciences, Emeryville, CA).

\section{Northern blot}

Ten micrograms of total RNAs were extracted (Chomczynski and Sacchi, 1987) from 21-d-old rat organs including brain, cerebellum, cochlea, eye, kidney, liver, muscle, and testis. Extracts were electrophoresed in a $0.8 \%$ agarose formaldehyde gel and transferred to a neutral nylon membrane in denaturing conditions (Löw and Rausch, 1994). After linearization of the plasmid, digoxigenin-labeled riboprobes were synthesized (SP6/T7 DIG RNA labeling kit, Boehringer Mannheim) according to the manufacturer's instructions and hybridized to the blot overnight at $68^{\circ} \mathrm{C}$. As a control for RNA degradation, the blot was stripped and hybridized with a digoxigenin-labeled glyceraldehyde-3-P dehydrogenase riboprobe.

\section{In situ hybridization}

Rat cochleas and vestibular end organs were removed and fixed as described previously (Knipper et al., 1998), embedded in OCT, and cut in $14 \mu \mathrm{m}$ cryosections. Sense and antisense riboprobes were obtained as described above (Northern blot), mixed with the hybridization buffer (Amersham Biosciences, Braunschweig, Germany) containing 50\% formamide, and hybridized to slides overnight at $55^{\circ} \mathrm{C}$. The sections were washed twice in $0.1 \times \mathrm{SSC}$ at $55^{\circ} \mathrm{C}$ for $30 \mathrm{~min}$ and processed for digoxigenin immunodetection following the manufacturer's instructions (Roche Biochemicals, Mannheim, Germany).

\section{Antibody production}

The $\mathrm{N}$ terminus of the mature, cleaved rat otospiralin $\left(\mathrm{NH}_{2}{ }^{-}\right.$ KPTPEEADPNAQ-COOH) was coupled to KLH and injected into rabbits for antisera production (Eurogentec, Seraing, Belgium). Antiserum SE1657 was obtained, and its specificity was checked by immunoblot analysis using the preimmune serum as a negative control.

\section{Western blotting}

Tissues were harvested in cold PBS and homogenized in sample buffer (Laemmli, 1970), and the lysates were centrifuged to remove detergentinsoluble material and separated on a $16.5 \%$ SDS-PAGE in Tris/Tricine (Schägger and Von Jagow, 1987). After gel electrophoresis, proteins were transferred electrophoretically to nitrocellulose membranes. Blots were incubated with SE1657 anti-otospiralin antibody diluted at 1:1000 according to Towbin et al. (1979) and visualized by chemiluminescence using a peroxidase-conjugated secondary antibody (Boehringer Mannheim). Polypeptide range marker was used for calibration (Bio-Rad, Hercules, CA).

\section{Immunohistochemistry}

For cochleas, 21-d-old rats were decapitated under deep anesthesia (Nembutal, $50 \mathrm{mg} / \mathrm{kg}$ ), and their cochleas were quickly removed, pierced at their apex, and fixed overnight in $4 \%$ paraformaldehyde. They were then decalcified for $4 \mathrm{~d}$ in $10 \%$ EDTA, dehydrated in ethanol, cleared, and embedded in paraffin. Paraffin sections $(7 \mu \mathrm{m})$ were deparaffinized, blocked in 30\% goat serum, and incubated with SE1657 anti-otospiralin antiserum diluted at 1:400. Bound primary antibodies were revealed by colorimetry using immunoperoxidase-conjugated secondary antibody (1: 100 ) following the manufacturer's instructions (Vector). For vestibules, 21-d-old rats were transcardially perfused with $4 \%$ paraformaldehyde and processed as described (Sage et al., 2000). Vibratome sections (50 $\mu \mathrm{m})$ were incubated with SE1657 anti-otospiralin antibody diluted at 1:200. Bound primary antibodies were detected using Texas Redconjugated anti-rabbit IgGs diluted at 1:200 (Jackson ImmunoResearch, West Grove, PA). Sections were observed under a Bio-Rad MRC1024 laser scanning confocal microscope equipped with a $40 \times$ oil-immersion objective lens of numerical aperture 1.4.

\section{Morphological studies}

For each of two animals, morphological investigations were performed on the right antisense oligonucleotide-treated cochlea and on the left untreated cochlea as a control. After the last electrophysiological test, animals were heavily anesthetized, and the cochleas were removec quickly and perfused with a freshly prepared fixative containing $3.5 \%$ glutaraldehyde in sodium cacodylate buffer $(0.1 \mathrm{M}), \mathrm{pH}$ 7.2. They were rinsed in cacodylate buffer, post-fixed in $2 \%$ osmic acid for $2 \mathrm{hr}$, rinsed twice again before dehydration, and embedded in Spurr resin at $70^{\circ} \mathrm{C}$. Blocks were trimmed to separate the different cochlear coils and remounted for transverse sections. Semithin sections were examined in Nomarski optics before thin sections $(80-100 \mathrm{~nm})$ were cut using a Leica-Reichert ultra-microtome. Grids, counterstained with uranyl acetate and lead citrate, were observed using a transmission electron microscope (Hitachi 7100). Three series of sections were taken from each block (two blocks per coil) so as to thoroughly examine at least six different levels of organ of Corti per cochlea.

\section{Antisense oligonucleotides}

A 14-mer phosphorothioate oligonucleotide (cobAS6 5'-CAGTAGGGCATGGC-3') corresponding to nucleotides c.116-c.103 of guinea pig otospiralin cDNA sequence was synthesized and PAGE-purified for the antisense experiments. As a control, we synthesized a second oligonucleotide with the same base composition in which the position of 4 nucleotides were permutated (cobAS6R 5'-ACCTAGGGGATGGC-3').

\section{Otospiralin downregulation in rats}

Two rats were anesthetized intraperitoneally with $0.3 \mathrm{ml} / \mathrm{kg}$ of sodium pentobarbital at $6 \%$ (Sanofi, Montpellier, France). The right bulla containing the cochlea and the middle ear was opened through a posterior auricular surgical procedure, and a gel foam (Gelita tampon, Braun) loaded with $2.5 \mu \mathrm{l}$ of a $600 \mu \mathrm{M}$ antisense oligonucleotide solution was placed in the middle ear. Compound action potentials (CAPs) were recorded from an electrode placed on the round window $4 \mathrm{~d}$ after the antisense treatment. Rats were killed at $5 \mathrm{~d}$, and expression of otospiralin was examined in Western blot.

\section{Surgery for otospiralin downregulation in guinea pigs}

Guinea pigs were anesthetized as above, and the vital parameters were tightly controlled (rectal temperature maintained at $38 \pm 1^{\circ} \mathrm{C}$ and heart rate monitored via EKG electrodes). The right bulla was postauricularly approached and opened to expose the cochlea, and a recording electrode was applied on the bony edge of the round window to prevent direct damage of the window membrane. A $0.2 \mathrm{~mm}$ diameter hole was then gently drilled in the basal turn of the scala tympani $(2 \mathrm{~mm}$ below the round window). A ring of glue was put on the tip of a glass pipette $(0.1$ $\mathrm{mm}$ diameter), and the tip was inserted into the hole using a micromanipulator until the ring of glue gave a leak-proof seal between the pipette and the cochlea, i.e., at $0.5 \mathrm{~mm}$ from the tip. The pipette was connected via a polyethylene tubing to an osmotic minipump (No. 2001, Alzet Corporation, Palo Alto, CA) filled with oligonucleotides diluted in perilymph and placed under the skin of the back of the animal. A reference electrode placed in the neck muscle and the round window electrode were soldered to a plug fixed on the skull. The perfusion was performed for $7 \mathrm{~d}$ at a rate of $1 \mu \mathrm{l} / \mathrm{hr}$, delivering a total amount of $10 \mathrm{nmol}$ of oligonucleotides.

\section{Guinea pig electrophysiology}

Compound action potential of the auditory nerve. Tone bursts with a 1 $\mathrm{msec}$ rise/fall time and an $8 \mathrm{msec}$ total duration generated by an arbitrary 
A

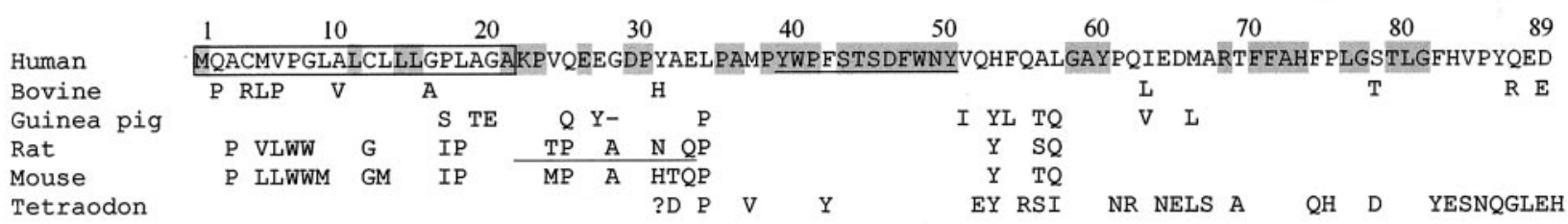

B

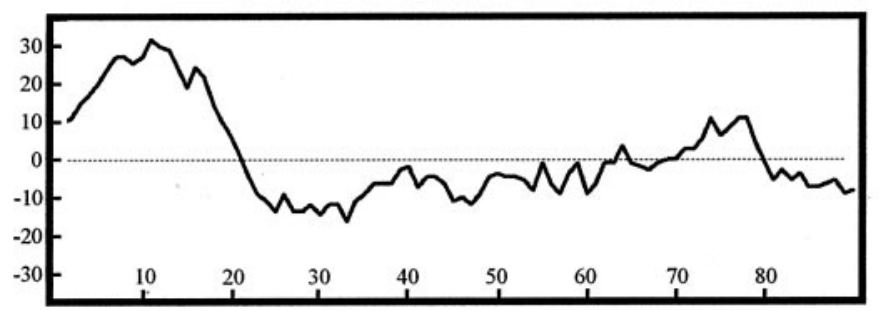

Figure 1. Sequence of human otospiralin compared with mammal and fish orthologs; hydropathic profile. $A$, The human otospiralin amino acid sequence is shown aligned with bovine, guinea pig, rat, mouse, and tetraodon sequences. Only changed amino acids are indicated in nonhuman sequences. Conserved amino acids in all six sequences are depicted in gray. The question mark indicates that the putative $\mathrm{N}$-terminal sequence of tetraodon (until amino acid 32) is unknown. The signal peptide is boxed, and the 12 amino acid stretch homologous with the p30 core shell nucleocapsid protein from retroviruses is underlined. Peptide 1657 used for antibody production is underlined in the rat sequence. $B$, Hydrophobicity profile of human otospiralin according to Kyte and Doolittle (1982) analyzed with a window of 17 . N-terminal hydrophobic domain corresponds to the signal peptide.

function generator (type 9100R, Lecroy Instruments) were used to elicit CAPs. The signals were passed through a programmable attenuator and presented to the ear in free field via a JBL 075 earphone. Nine frequencies $(2,4,6,8,10,12,16,20$, and $26 \mathrm{kHz})$ were examined, with each frequency increasing levels in $5 \mathrm{~dB}$ steps from 0 to $100 \mathrm{~dB}$ sound pressure level (SPL) at a presentation rate of 10 bursts per second. Cochlear responses were amplified (gain 2000) by a differential amplifier (Grass P511K), and the signals were filtered (bandpass $100 \mathrm{~Hz}-3 \mathrm{kHz}$ ) and averaged (256 tests) on a PC Pentium computer, $100 \mathrm{MHz}$ (Dell Dimension). The sampling rate of the analog to digital converter was $50 \mathrm{kHz}$, with a dynamic range of 12 bits and 1024 samples per record. CAPs were measured peak-to-peak between the negative (N1) and the following positive value (P1). The thresholds were defined as the level of dB SPL needed to elicit a measurable response range from 2 to $5 \mu \mathrm{V}$.

Distortion product acoustic emissions. Distortion product acoustic emissions (DPOAEs) were recorded using the CUBeDIS system. Continuous pure tones were elicited ( $\mathrm{f} 2 / \mathrm{f} 1=1.2$; intensity of $\mathrm{f} 1=\mathrm{f} 2=60 \mathrm{~dB}$ SPL reference $2.10-5 \mathrm{~Pa}$; $\mathrm{f}$ varying between $20 \mathrm{kHz}$ and $2 \mathrm{kHz}$ with 4 points per octave) and recorded with a three-channel acoustic probe (ER-10C, Etymotic Research) placed in the external auditory canal. The acoustic signal was amplified by a preamplificator (ER-10C DPOAE probe driver preamp, Etymotic Research), and data were analyzed with the CUBeDIS software.

Endocochlear potential measurement. after a ventrolateral approach of the cochlea, the bone over the basal turn scala media was shaved to perform a small fenestra through the thinned bone. A glass microelectrode filled with $3 \mathrm{M} \mathrm{KCl}$ and connected to a direct current amplifier (model KS-700, World Precision Instrument) was passed through the fenestra and into the scala media to record the endocochlear potential.

\section{RESULTS}

\section{Otospiralin is a novel inner ear protein}

Part of the otospiralin mRNA was initially identified by systematic sequencing of a rat cochlea cDNA library (Soto-Prior et al., 1997). Using this sequence information, we screened cDNA libraries and PCR-amplified genomic DNA to obtain the fulllength mRNA sequences of human (AY062256), rat (AY062254), mouse (AY062257), and guinea pig (AY062255) otospiralin, and found in Expressed Sequence Tag databases that of bovine
(BE722880) species. These mRNAs encode an 89 amino acidlong polypeptide except for the guinea pig, which lacks the 28th amino acid (Fig. $1 A$ ). In all species the protein has a 21 amino acid-long peptide signal showing characteristic uncharged and hydrophobic residues. In addition, the AXA peptidase consensus (Folz et al., 1988) is present in human, bovine, rat, and mouse sequences. Cleavage of this signal peptide leaves a 68-residue mature protein (67 in guinea pig) that is hydrophilic on average (Fig. $1 B$ ), with no evidence of either transmembrane domain or glycophosphatidyl inositol anchorage sequence, indicating that it is likely to be secreted.

The overall identity of the uncleaved human otospiralin with the four other mammalian species ranges from $87.6 \%$ (bovine) to $79.8 \%$ (mouse). However, most of the mature, cleaved protein is highly conserved, in particular residues 35-50 with $100 \%$ identity and residues 58-86 with $100 \%$ similarity (only three conservative changes). We found an additional protein sequence translated from the Tetraodon nigroviridis fish genomic clone AL267179 that appears as an N-terminal-truncated otospiralin ortholog sequence (Fig. 1A). Comparison with the human otospiralin reveals that the most conserved region is also located between residues 35 and 50 (87.5\% identity). In addition, in this stretch, residues 39-50 are similar to a motif found in the p30 core shell nucleocapsid protein (GAG polypeptide) from the endogenous type $\mathrm{C}$ retroviruses, the function of which is presently unknown.

\section{Otospiralin is produced by mesenchymal inner ear fibrocytes}

Because adult human cochlear tissue was not available, we studied the mRNA and protein expression of otospiralin in the rat. Northern blot analysis revealed a single 0.62-kb-long mRNA strongly expressed in the cochlea (Fig. $2 A$ ) but absent in brain, cerebellum, eye, kidney, liver, muscle, and testis. Western blot 
A
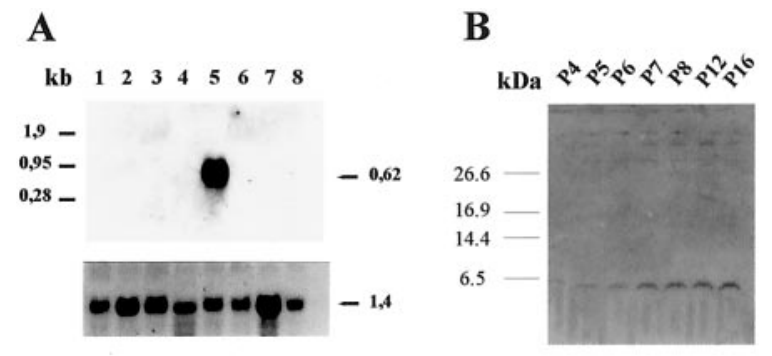

$\mathbf{C}$

D

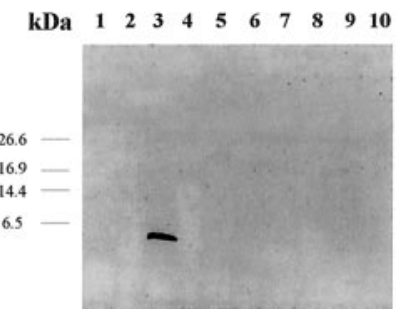

Figure 2. Otospiralin is inner ear specific and expressed from $\mathrm{P} 4$ in rats. $A$, Northern blot hybridized to a digoxigenin-labeled antisense riboprobe (pCO8) spanning the whole coding sequence of rat otospiralin. Ten $\mu \mathrm{g} /$ lane of total RNA from rat tissues were loaded as follows: 1, brain; 2 , cerebellum; 3 , eye; 4, kidney; 5 , cochlea; 6 , liver; 7 , muscle; 8 , testis. A single $0.62 \mathrm{~kb}$ mRNA is visible in the cochlea. The bottom panel shows the same blot hybridized with a G3PDH riboprobe with a $1.4 \mathrm{~kb}$ mRNA in every tissue. $B$, Western blot with rat cochleas at various postnatal $(P)$ stages indicated above each lane and incubated with SE1657 antiotospiralin antiserum. A $6.4 \mathrm{kDa}$ signal is detectable from $\mathrm{P} 4$ and progressively increases until P16. $C$, Western blot as in $B$ shows expression of otospiralin in vestibule (1) and cochlea (2). $D$, Western blot as in $B$ with various rat tissues. 1 , Cochlear nucleus; 2 , cochlear nerve; 3 , cochlea; 4 , spinal cord; 5 , muscle; 6 , eye; 7 , cerebral cortex; 8 , cerebellum; 9 , diencephalon; 10 , olfactory bulb.

analysis of cochlear extracts disclosed a $6.4 \mathrm{kDa}$ product detected as early as postnatal day (P) 4 and gradually increasing until P16 (Fig. 2B). It was consistently found at the adult stage (data not shown). Otospiralin was also detected in the vestibule (Fig. 2C) but was absent from various parts of the brain (olfactory bulb, diencephalon, striatum, hippocampus, cortex, cerebellum), from cochlear nerve and nucleus, and from spinal cord, eye, muscle, heart, liver, kidney, spleen, testis, lung, small intestine, thyroid, and skin (Fig. 2D) (data not shown). Otospiralin is thus strictly confined to cochlear and vestibular peripheral organs.

To determine which cell type produces otospiralin in the inner ear structures, we performed in situ hybridization on rat tissues. In the cochlea, numerous cells from the spiral ligament residing behind the stria vascularis and from the spiral limbus expressed the mRNA (Fig. 3A). The glial cells surrounding the spiral ganglion neurons also expressed the mRNA but to a lower level than the spiral ligament and spiral limbus. In the vestibule, the mRNA was present in cells located to the stroma underlying the utricle and crista sensory epithelia, around vestibular nerve fibers (Fig. $3 F$ ). It was also present in the cristae beneath the transitional epithelium and dark cell areas, and in the subepithelial zone of the walls of semicircular canals (Fig. 3C) and maculae. No signal was observed in the dark cells. In both the cochlea and vestibule, no mRNA was detected in the sensory cells or the endolymph-producing cells.

Expression studies of the protein by immunohistochemistry were compared with the results of in situ hybridization. As expected, in the cochlea, cells from the spiral ligament and spiral
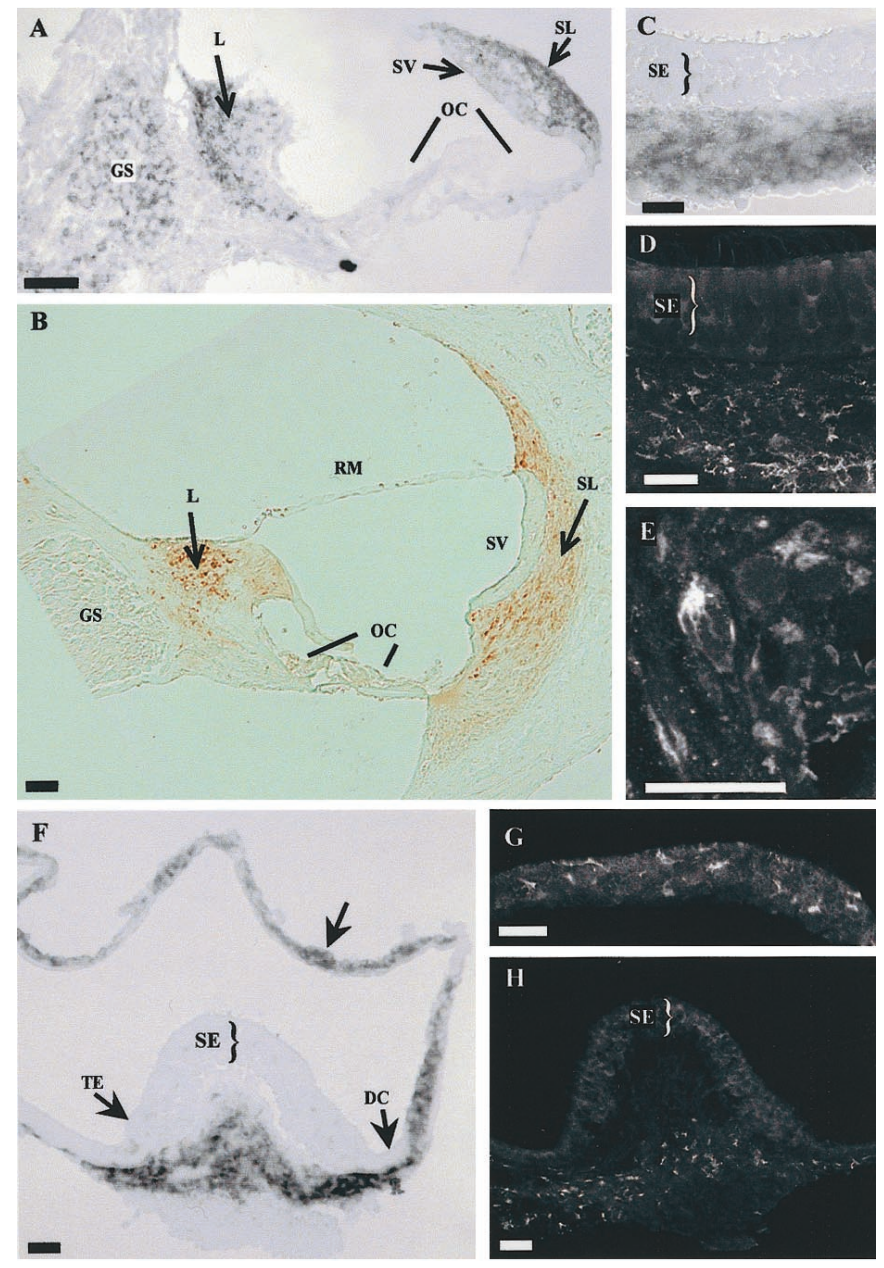

Figure 3. Expression of otospiralin in rat cochlea and vestibule. In situ hybridization $(A, C, F)$ and immunohistochemistry $(B, D, E, G, H)$ of cochlea $(A, B)$, utricle $(C, D)$, and crista and semicircular canal $(F, G, H)$. In the cochlea $(A)$, digoxigenin-labeled antisense riboprobe (pCO8) hybridized to tissue sections shows otospiralin mRNA in fibrocytes of spiral limbus and spiral ligament, and to a lesser extent in glial cells from the spiral ganglion. In the vestibule $(C, F)$, the same probe detects the mRNA in fibrocytes from subepithelial regions of the utricle $(C)$ and crista $(F)$. Otospiralin mRNA is also present in cells of the semicircular canal walls $(F$, arrow $)$. In the cochlea $(B)$, SE1657 antiserum detects otospiralin in fibrocytes of the spiral limbus, spiral ligament, and suprastrial zone. No protein is found in the spiral ganglion, organ of Corti, or stria vascularis. In the vestibule, otospiralin is detected in the stroma beneath the sensory epithelia of the utricle $(D)$ and cristae $(H)$. In the utricular and semicircular canal walls $(G)$, fibrocytes are immunostained. The stained fibroblasts have a stellar $(E)$ or elongated $(G)$ shape. Scale bar, $20 \mu \mathrm{m}$. $D C$, Dark cell area; $G S$, spiral ganglion; $L$, spiral limbus; $O C$, organ of Corti; $R M$, Reissner's membrane; $S E$, sensory epithelium; $S L$, spiral ligament; $S V$, stria vascularis; $T E$, transitional epithelium.

limbus were intensely stained (Fig. 3B). However, glial cells from the spiral ligament were unstained, indicating that they do not produce otospiralin (Fig. $3 B$ ). In the vestibule, the immunostaining was observed in cells located to the stroma below the macular and crista sensory epithelia and in the subepithelial layer of the walls of semicircular canals and maculae (Fig. 3D, G,H), matching the mRNA expression found by in situ hybridization. In both organs, the immunostained cells appeared as fibrocytes that display a heterogeneous morphology from stellar to elongated shapes (Fig. 3E, G). 


\section{Otospiralin downregulation causes vestibular syndrome and deafness}

To downregulate the expression of otospiralin in the inner ear, we used antisense oligonucleotides directed against the otospiralin mRNA. In a first set of experiments in rats, a piece of gel foam loaded with oligonucleotides $(1.6 \mathrm{nmol}$ in $2.5 \mu \mathrm{l})$ was placed directly on the round window, allowing for the diffusion to the cochlea and vestibule. A vestibular syndrome (head tilt) was first observable $2 \mathrm{~d}$ after the surgery and became prominent at $4 \mathrm{~d}$ after surgery, with a head tilt $\left(45^{\circ}\right.$ on the side of the operated ear) and a waltzing behavior (animals circling around the side of the operated ear). In addition, the rats showed an increased threshold of 40-60 dB SPL across frequencies (data not shown). As seen in Western blot, the cochlea from the treated ear of one rat harvested $5 \mathrm{~d}$ after application of oligonucleotides contained significantly less otospiralin than that of the untreated ear (Fig. 4A), whereas the Coomassie blue protein patterns were similar in both ears. This indicated that the antisense treatment of otospiralin mRNA specifically downregulated the otospiralin protein.

To further examine the implications of the loss of otospiralin, we used guinea pigs, because cochlear perfusion was not possible in rats. Using an osmotic minipump, we perfused the right cochlea of six animals for $7 \mathrm{~d}$ with a total of $10 \mathrm{nmol}$ of antisense oligonucleotides. The CAP audiogram was measured before and after $1,2,3,5,10,15$, and $30 \mathrm{~d}$ after minipump implantation in awake animals. The variance analysis and Newman-Keuls multiple range test showed a significant change in the CAP thresholds the first day after the beginning of cochlear perfusion in the high-frequency side of the audiogram, extending to all frequencies on the following days in all six animals (Table 1). In four of six animals, the CAPs were irreversibly abolished within the time course of the perfusion (Fig. 4B). By contrast, the cochlear perfusion of four guinea pigs with an oligonucleotide of the same base composition as the antisense one but differing by permutations of four nucleotides did not result in any significant change in the CAP thresholds (Table 2, Fig. 4C).

To assess possible effects of otospiralin downregulation on outer hair cell physiology, we measured the distortion products of acoustic emissions that are generated by the active mechanisms (electromotility) of these cells. From the three tested animals perfused with the antisense oligonucleotide, the amplitude of the 2f1-f2 distortion product was decreased on day 1 after perfusion and fell into the noise floor by day 3, whatever the pace of the CAP threshold increase, indicating that outer hair cells were not functioning (Fig. 4D). In three control animals, the amplitude of the $2 \mathrm{f} 1-\mathrm{f} 2$ product remained unchanged during the time course of the perfusion $(7 \mathrm{~d})$ and up to 1 month after the micropump implantation (Fig. $4 E$ ). In one deaf animal after $5 \mathrm{~d}$ of perfusion, the endolymphatic potential was measured and found to be normal (i.e., $+86 \mathrm{mV}$ ), suggesting that deafness was not caused by the lack of potassium in the endolymph but, taking into account the profound deafness and absence of distortion products, by a loss of hair cell function.

\section{Deafness is caused by degeneration of hair cells}

Both cochleas from two guinea pigs with abolished CAPs were examined by electron microscopy. The first deaf guinea pig was killed after $5 \mathrm{~d}$ of perfusion. All sections randomly made all over the cochlear spiral from the antisense-treated side showed a severe degeneration of the organ of Corti, accounting for the absence of responses at all frequencies. By contrast, the tectorial membrane and the stria vascularis, often involved in early degen-
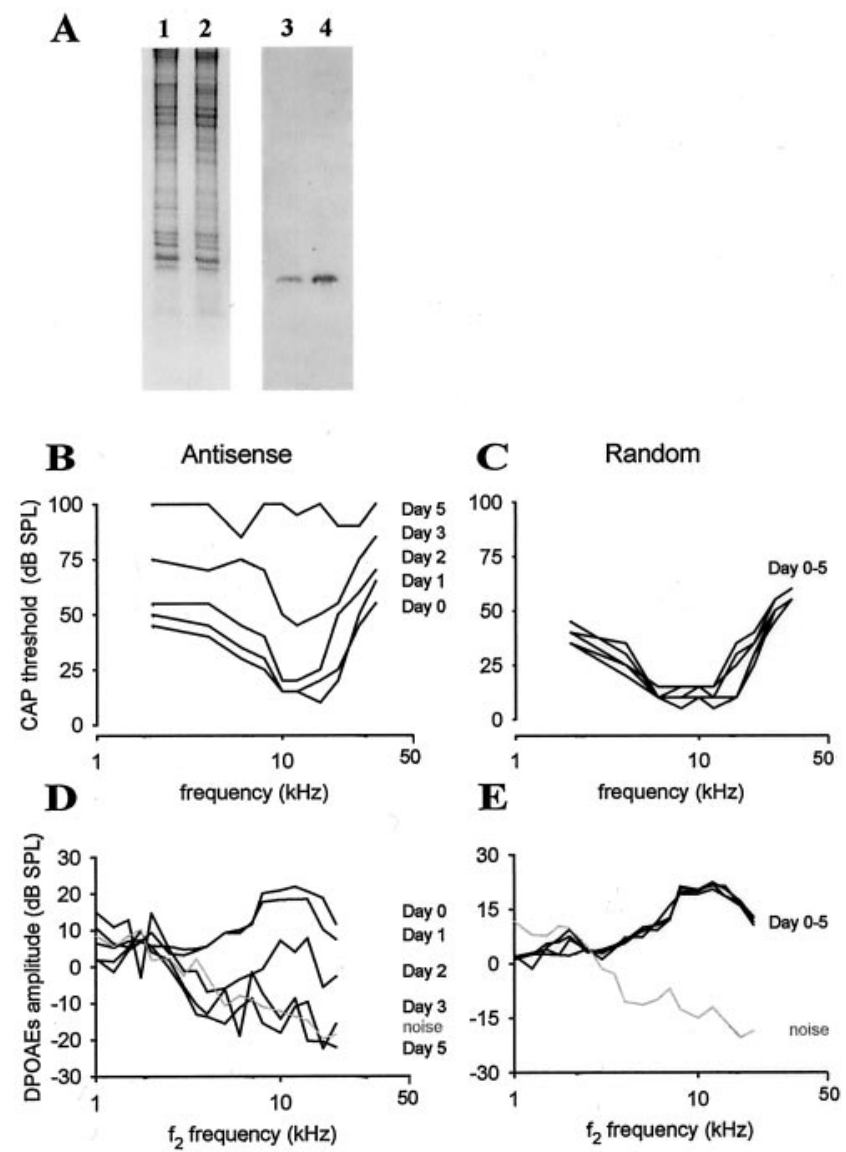

Figure 4. Downregulation of otospiralin leads to deafness. $A$, Coomassie blue-stained SDS-PAGE $(1,2)$ and Western blot $(3,4)$ incubated with SE1657 anti-otospiralin antiserum. Extracts from the right cochlea treated with antisense mRNA oligonucleotides $(1,3)$ and from the left untreated cochlea $(2,4)$ of the same rat were analyzed. As shown on Coomassie blue-stained gel, equal amounts of material from both cochleas were loaded, but much less otospiralin was detected in the treated cochlea as compared with the untreated one. $B$, Intracochlear application of $10 \mathrm{nmol}$ of antisense oligonucleotide directed against otospiralin for $7 \mathrm{~d}$ in guinea pigs via an osmotic minipump. Diagram shows the compound action potential $(C A P)$ thresholds in $\mathrm{dB}$ SPL plotted with the frequency from one animal. There is an elevation of the CAP threshold of the auditory nerve $2 \mathrm{~d}$ after the perfusion start (Day 2). Virtually no CAP could be measured at Day 5. C, Guinea pig treated as in $B$ with $10 \mathrm{nmol}$ of oligonucleotides of the same base composition but differing by permutations of four nucleotides. There is no significant effect on the CAP thresholds. $D$, Same guinea pig as in $B$. Diagram shows the amplitude of the distortion product otoacoustic emissions (DPOAEs) plotted with the f2 frequency. The DPOAE amplitudes decreased at Day 1 and fell into the noise floor at Day 3. E, Same guinea pig as in $C$. There is no effect on the DPOAE audiogram during the time course of the perfusion and up to 1 month after the micropump implantation.

erating processes, were not affected. The spiral ligament and spiral limbus structures were also preserved, but fibrocytes were damaged. In semithin sections, the organ of Corti appeared as a compact epithelium in which the tunnel and other spaces were filled by cellular material with no distinguishable hair cells or Deiters' cells (Fig. $5 A$ ), whereas the contralateral organ of Corti from the untreated side did not show any lesion (Fig. 5B). Thin sections of the treated cochlea observed in transmission electron microscopy revealed virtually no outer hair cells or supporting cells but a densely packed cellular material, with pieces of outer pillars, and some apoptotic nuclei (Fig. 5D). On the luminal side, 
Table 1. Mean threshold shift and SE during application of antisense otospiralin oligonucleotides

\begin{tabular}{|c|c|c|c|c|c|c|c|c|c|}
\hline \multirow[b]{2}{*}{ Days $^{a}$} & \multicolumn{9}{|c|}{ Frequency in $\mathrm{kHz}$} \\
\hline & 2 & 4 & 6 & 8 & 10 & 12 & 16 & 20 & 26 \\
\hline 1 & $9.0^{b} \pm 3.5^{c}$ & $5.0 \pm 3.8$ & $8.0 \pm 3.5$ & $10 \pm 2.8^{*}$ & $12 \pm 3.0^{*}$ & $16 \pm 2.7^{*}$ & $15 \pm 4.0^{*}$ & $14 \pm 3.0^{*}$ & $13 \pm 3.3^{*}$ \\
\hline 2 & $19 \pm 7.4^{*}$ & $22 \pm 6.7^{*}$ & $25 \pm 6.3^{*}$ & $22 \pm 3.3^{*}$ & $23 \pm 7.0^{*}$ & $23 \pm 7.0^{*}$ & $19 \pm 6.7^{*}$ & $21 \pm 6.8^{*}$ & $26 \pm 4.3^{*}$ \\
\hline 3 & $30 \pm 14.7^{*}$ & $33 \pm 14.0^{*}$ & $39 \pm 13.2^{*}$ & $40 \pm 12.6^{*}$ & $40 \pm 12.5^{*}$ & $38 \pm 12.9^{*}$ & $31 \pm 14.5^{*}$ & $34 \pm 14.2^{*}$ & $36 \pm 13.6^{*}$ \\
\hline 5 & $52 \pm 16.4^{*}$ & $55 \pm 15.3^{*}$ & $49 \pm 14.6^{*}$ & $55 \pm 15.1^{*}$ & $56 \pm 14.7^{*}$ & $52 \pm 15.2^{*}$ & $49 \pm 17.1^{*}$ & $51 \pm 15.5^{*}$ & $49 \pm 16.2 *$ \\
\hline
\end{tabular}

Guinea pigs received $10 \mathrm{nmol}$ of oligonucleotides for $7 \mathrm{~d}$ via intracochlear perfusion.

*Indicates the significance, $p<0.05$.

${ }^{a}$ Number of days after perfusion start.

${ }^{b}$ Mean threshold shift in dB SPL.

${ }^{c} n=6$.

Table 2. Mean threshold shift and SE during application of random oligonucleotides

Frequency in $\mathrm{kHz}$

\begin{tabular}{|c|c|c|c|c|c|c|c|c|c|}
\hline Days $^{a}$ & 2 & 4 & 6 & 8 & 10 & 12 & 16 & 20 & 26 \\
\hline 1 & $0.0^{b} \pm 4.0^{c}$ & $-3.3 \pm 1.1$ & $0.0 \pm 2.0$ & $3.3 \pm 3.1$ & $3.3 \pm 1.1$ & $3.3 \pm 1.1$ & $-1.6 \pm 3.1$ & $1.6 \pm 1.1$ & $-1.6 \pm 3.1$ \\
\hline 2 & $-1.6 \pm 3.1$ & $-1.0 \pm 2.2$ & $5.0 \pm 2.0$ & $6.6 \pm 3.1$ & $5.0 \pm 2.0$ & $3.3 \pm 1.1$ & $-3.3 \pm 3.1$ & $1.6 \pm 1.1$ & $1.6 \pm 2.3$ \\
\hline 3 & $-1.3 \pm 3.1$ & $-1.0 \pm 3.1$ & $-6.0 \pm 3.1$ & $-3.3 \pm 4.2$ & $0.0 \pm 3.5$ & $-1.6 \pm 1.1$ & $-1.0 \pm 4.2$ & $-1.6 \pm 1.1$ & $-1.3 \pm 2.3$ \\
\hline 5 & $-6.6 \pm 4.2$ & $-1.0 \pm 3.1$ & $1.6 \pm 1.1$ & $-1.6 \pm 6.2$ & $-1.6 \pm 5.1$ & $-1.6 \pm 4.2$ & $-1.0 \pm 3.5$ & $0.0 \pm 4.0$ & $-1.6 \pm 1.1$ \\
\hline
\end{tabular}

Guinea pigs were given $10 \mathrm{nmol}$ of oligonucleotides for $7 \mathrm{~d}$ via intracochlear perfusion.

*Indicates the significance, $p<0.05$.

${ }^{a}$ Number of days after perfusion start.

${ }^{b}$ Mean threshold shift in dB SPL.

${ }^{c} n=4$.

remnants of the outer hair cell cuticular plates and stereocilia were sparse. The inner hair cell area was slightly less damaged. In some places, close to a twisted inner pillar and a hypertrophied phalange cell, inner hair cells were still identifiable, but the cuticular plates bore abnormal stereocilia (Fig. 5C). A striking feature, found in some sections, was the presence of an abnormal cell type within the inner spiral bundle sending processes interposed between afferent neurites and inner hair cells. Auditory nerve endings, after losing their target, were seen reaching the lumen (Fig. $5 C$ ). In the spiral limbus and spiral ligament from the treated cochlea, fibrocytes showed cytoplasmic vacuolization and shrinkage accompanying chromatin condensation in the nucleus (Fig. 5E), whereas fibrocytes from the untreated cochlea remained normal (Fig. $5 F$ ). The second guinea pig became deaf at the end of the perfusion time course $(7 \mathrm{~d})$ and did not show any sign of functional restoration in the following weeks. It was killed at day 30 after implantation. Degeneration of the organ of Corti with the same features as in the primary animal was also observed (data not shown). We concluded that the loss of otospiralin was dramatically affecting the organ of Corti, with some damage to spiral ligament and spiral limbus fibrocytes.

\section{DISCUSSION}

We report on the discovery of otospiralin, a small inner earspecific protein produced by fibrocytes of the spiral ligament and spiral limbus in the cochlea and subepithelial regions of the maculae and semicircular canals in the vestibule. Several features indicate that otospiralin is involved in a dedicated function of the inner ear fibrocytes that must be important for cochleovestibular physiology. Indeed, otospiralin is specific for the inner ear. In addition, downregulation of otospiralin in guinea pigs causes a rapid and severe degeneration of the organ of Corti leading to an irreversible deafness. Elucidation of the function of otospiralin will thus help in deciphering the roles of these intriguing fibrocytes.

Analysis of the sequence of otospiralin shows that this novel protein does not match any well characterized protein, except for a small part (12 residues) that is homologous to a motif present at the N-terminal end of the p30 core shell nucleocapsid protein (gag) from type $\mathrm{C}$ retroviruses. Remarkably, these 12 residues are part of the 16 amino acid stretch that is very conserved in fish and mammals, suggesting that this region is of primary importance for the function. p30 is necessary for virion assembly (Schwartzberg et al., 1984), and mutations in a conserved domain located in the central region of the protein lead to a loss of the infection capacity (Miller and Verma, 1984). The function of the $\mathrm{N}$-terminal end of p30 remains unknown, however. Mutagenesis experiments in this part of p30 addressing the question of its role in retroviral infection may be of help in understanding the function of otospiralin.

The decrease in otospiralin content of the inner ear causes loss in cochlea sensitivity, as shown by the dramatic increase in the CAP thresholds and also by the absence of acoustic otoemissions that more specifically reflect outer hair cell dysfunction. Examination of the cochleas in electron microscopy revealed that outer hair cells and, for the most part, inner hair cells disappeared. There are many situations in which hair cells degenerate. Loss of these cells occurs in acoustic trauma (Spoendlin and Braun, 1973) and in ototoxic drug administration (Hawkins, 1959) in a dosedependent manner (Lenoir and Puel, 1987). In addition, genetic defects affecting stereocilia (Osako and Hilding, 1971; Shnerson et al., 1983; Sjöström and Anniko, 1990; Probst et al., 1998; Self et al., 1999; Alagramam et al., 2000; Littlewood Evans and Mül- 

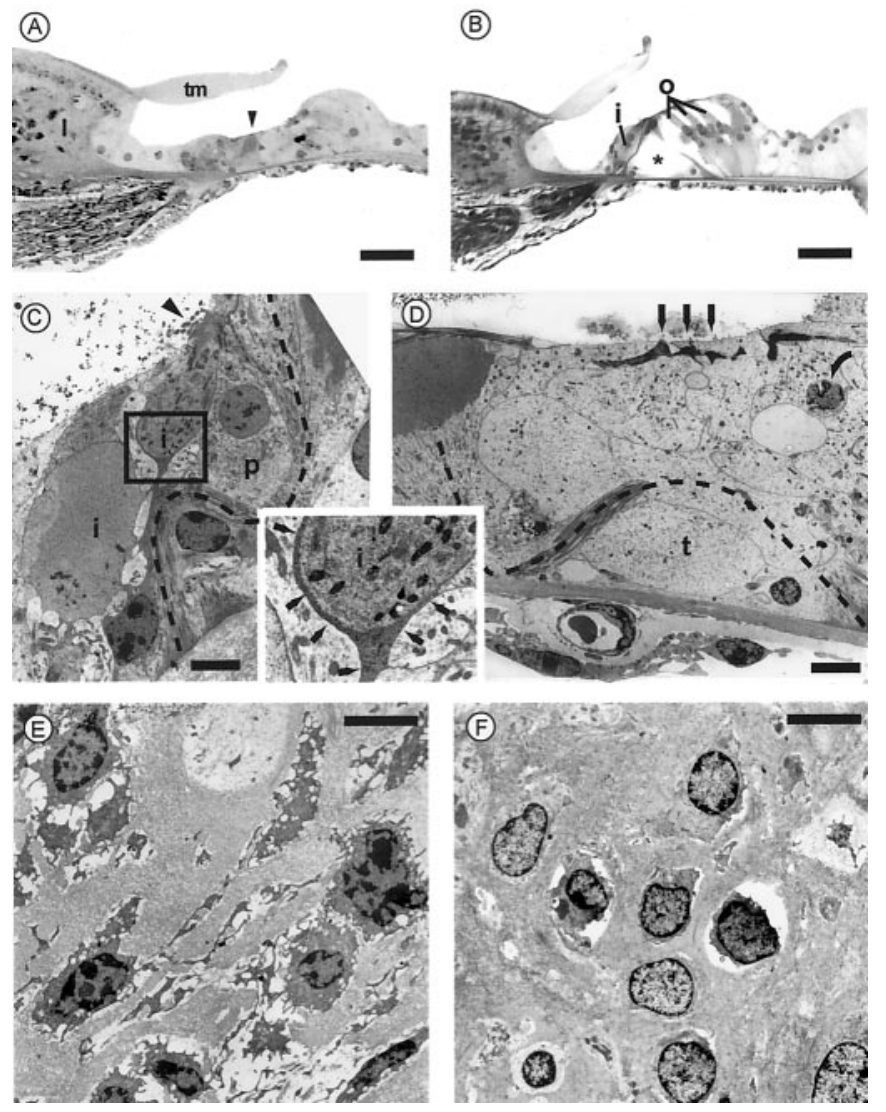

Figure 5. Degeneration of hair cells and organ of Corti in guinea pig cochleas with downregulated otospiralin. The top panel shows semithin (3 $\mu \mathrm{m})$ sections at the base of the second turn of the organ of Corti from antisense oligonucleotide-treated $(A)$ and untreated $(B)$ cochleas of the same guinea pig. As compared with the normal side, the organ of Corti in $A$ is totally degenerated. At this magnification, only remnants of the pillars (arrowhead) are recognizable underneath a normal-looking tectorial membrane. The untreated side in $B$ shows the normal organ of Corti, with one inner hair cell $(i)$ and three outer hair cells $(o)$ on each side of the pillars forming the tunnel of Corti (asterisk). Scale bar, $30 \mu \mathrm{m}$. The middle panel shows transmission electron micrographs at the level of the organ of Corti from the antisense oligonucleotide-treated cochlea. $C$, The dark cytoplasm of a degenerating inner hair cell $(i)$ is recognizable, together with remnants of its stereocilia (arrowhead). Nerve endings (auditory dendrites) still surround the cell body split in two parts in this section. However, as shown in higher magnification (inset), a thin process from a supporting cell, possibly glial (thin arrows), separates the inner hair cell from neurites, preventing synaptic contact. Note the twisted inner pillar (dotted line) and a hypertrophied phalangeal cell $(p)$. D, On the outer hair cell side, neither outer hair cells nor Deiters' cells are recognizable. Only remnants of the outer hair cell cuticular plates and stereocilia (arrows) can be distinguished on the top of a compact epithelium. The outer pillar is broken, and its twisted route can be followed up to the head of the inner pillar (dotted line). The space of the tunnel of Corti $(t)$ is filled with cellular material. One apoptotic nucleus is shown (curved arrow). Scale bars, $5 \mu \mathrm{m}$. Bottom panel shows transmission electron micrographs at the level of the spiral limbus from the antisense oligonucleotide-treated $(E)$ and untreated $(F)$ cochleas from the same guinea pig. $E$, Fibrocytes show severe degenerating changes with retraction and vacuolization of the cytoplasm and nucleus resembling the first stage of apoptosis. $F$, Fibrocytes have a normal appearance, although cytoplasm retraction is sometimes observed. Scale bars, $5 \mu \mathrm{m}$.

ler, 2000; Zheng et al., 2000) and ion transport in hair cells (Street et al., 1998) or in stria vascularis (Vetter et al., 1996; Delpire et al., 1999) cause the degeneration of the organ of Corti. The pace at which hair cells and supporting cells in the organ of Corti degenerate is variable, being as short as 1-2 weeks in disorders affecting primarily the stria vascularis (Vetter et al., 1996; Delpire et al., 1999). In this latter case, a collapse of tectorial and Reissner membranes over the organ of Corti is observed that could accelerate the degenerating process. In the present study, the otospiralin deprivation must have been highly insulting because most of the hair cells were lost by $5 \mathrm{~d}$ after the beginning of the antisense treatment in one representative animal.

Apart from the presence of an abnormal cell type interposed between neurites and inner hair cells that could correspond to a repair response, which perhaps is characteristic of this pathological model, the degeneration observed followed a classical pattern, because outer hair cells and supporting structures were more affected than inner hair cells. Signs of apoptosis and phalangeal cell hypertrophy as encountered in drug-induced ototoxicity (Lenoir et al., 1999) were also present. There are several pathological mechanisms that could generate such a pattern of degeneration. One possibility is that downregulation of otospiralin could cause a modification in the endolymph composition. In our experiment, the structures of the stria vascularis and of Reissner and tectorial membranes were unchanged, suggesting that there was no dramatic change in production and volume of the endolymphatic compartment. In addition, the normal endolymphatic potential found in one deaf animal suggested that potassium was not lacking. One cannot exclude however that the absence of otospiralin could change other ionic or non-ionic components of the endolymph, which would not have a direct effect on fluid circulation in the endolymphatic compartment but would perturb hair cell metabolism. A second possibility is that downregulation of otospiralin could impair hair cell functioning by itself. Indeed, because otospiralin is probably secreted, it could reach the neuroepithelium and exert its action, either directly on hair cells or through supporting cells or neurons. Noteworthy is the fact that no abnormality was seen on either afferent or efferent neurites within the organ of Corti or in myelinated fibers and spiral ganglion neurons. Finally, the lack of otospiralin could alter the fibrocytes themselves or their environment, which in turn may modify important factors for hair cells, or ion homeostasis. The vacuolization of some fibrocytes from the spiral ligament and spiral limbus, perhaps the otospiralin-producing cells, is relevant to this hypothesis. Future experiments searching for a receptor or protein partners of otospiralin will help in deciding what are its target cells and in deciphering the pathological mechanism that occurs in otospiralin deprivation.

Interestingly, some features of otospiralin resemble observations made with cochlin. Cochlin is another putatively secreted, novel inner protein with unknown function expressed in mesenchymal nonsensory tissues surrounding the neuroepithelium in chicken (Robertson et al., 1998). In addition, mutations in the cochlin gene cause nonsyndromic human deafness and vestibular dysfunction (Robertson et al., 1998; Fransen et al., 1999). On the basis of these observations, we anticipate that genetic defects leading to otospiralin loss of function could cause human deafness and vestibular dysfunction.

\section{REFERENCES}

Alagramam KN, Zahorsky-Reeves J, Wright CG, Pawlowski KS, Erway LC, Stubbs L, Woychik RP (2000) Neuroepithelial defects of the inner ear in a new allele of the mouse mutation Ames waltzer. Hear Res 148:181-191.

Chomczynski P, Sacchi N (1987) Single-step method of RNA isolation by acid guanidinium thiocyanate-phenol-chloroform extraction. Anal Biochem 162:156-159.

Cohen-Salmon, M, Frenz, D, Liu, W, Verpy, E, Voegeling, S, Petit C 
(2000) Fdp, a new fibrocyte-derived protein related to MIA/CD-RAP, has an in vitro effect on the early differentiation of the inner ear mesenchyme. J Biol Chem 275:40036-40041.

Couloigner V, Fay M, Djelidi S, Farman N, Escoubet B, Runembert I, Sterkers O, Friedlander G, Ferrary E (2001) Location and function of the epithelial Na channel in the cochlea. Am J Physiol Renal Physiol 280:F214-222.

Delpire E, Lu J, England R, Dull C, Thorne T (1999) Deafness and imbalance associated with inactivation of the secretory $\mathrm{Na}-\mathrm{K}-2 \mathrm{Cl} \mathrm{co}-$ transporter. Nat Genet 22:192-195.

Everett LA, Morsli H, Wu DK, Green ED (1999) Expression pattern of the mouse ortholog of the Pendred's syndrome gene (Pds) suggests a key role for pendrin in the inner ear. Proc Natl Acad Sci USA 96:9727-9732.

Folz RJ, Nothwehr SF, Gordon JI (1988) Substrate specificity of eukaryotic signal peptidase. Site-saturation mutagenesis at position -1 regulates cleavage between multiple sites in human pre (delta pro) apolipoprotein A-II. J Biol Chem 263:2070-2078.

Fransen E, Verstreken M, Verhagen WI, Wuyts FL, Huygen PL, D'Haese P, Robertson NG, Morton CC, McGuirt WT, Smith RJ, Declau F, Van de Heyning PH, Van Camp G (1999) High prevalence of symptoms of Ménière's disease in three families with a mutation in the $\mathrm{COCH}$ gene. Hum Mol Genet 8:1425-1429.

Harter C, Ripoll C, Lenoir M, Hamel CP, Rebillard G (1999) Expression pattern of mammalian cochlea outer hair cell (OHC) mRNA: screening of a rat OHC cDNA library. DNA Cell Biol 18:1-10.

Hawkins Jr JE (1959) The ototoxicity of kanamycin. Ann Otol Rhinol Laryngol 68:698-715.

Kikuchi T, Kimura RS, Paul DL, Takasaka T, Adams JC (2000) Gap junction systems in the mammalian cochlea. Brain Res Brain Res Rev 32:163-166.

Knipper M, Bandtlow C, Gestwa L, Kopschall I, Rohbock K, Wiechers B, Zenner HP, Zimmermann U (1998) Thyroid hormone affects Schwann cell and oligodendrocyte gene expression at the glial transition zone of the VIIIth nerve prior to cochlea function. Development 125:3709-3718.

Kyte J, Doolittle RF (1982) A simple method for displaying the hydropathic character of a protein. J Mol Biol 157:105-132.

Laemmli UK (1970) Cleavage of structural proteins during the assembly of the head of bacteriophage T4. Nature 227:680-685.

Lautermann J, Ten Cate WJ, Altenhoff P, Grummer R, Traub O, Frank H, Jahnke K, Winterhager E (1998) Expression of the gap-junction connexins 26 and 30 in the rat cochlea. Cell Tissue Res 294:415-420.

Lenoir M, Puel J-L (1987) Dose-dependent changes in the rat cochlea following aminoglycoside intoxication. Histological study. Hear Res 26:199-209.

Lenoir M, Daudet N, Humbert G, Renard N, Gallego M, Pujol R, Eybalin M, Vago P (1999) Morphological and molecular changes in the inner hair cell region of the rat cochlea after amikacin treatment. J Neurocytol 28:925-937.

Littlewood Evans A, Müller U (2000) Stereocilia defects in the sensory hair cells of the inner ear in mice deficient in integrin $\alpha 8 \beta 1$. Nat Genet 27:424-428.

Miller AD, Verma IM (1984) Two base changes restore infectivity to a noninfectious molecular clone of moloney murine leukemia virus (pMLV-1). J Virol 49:214-222.

Mothe AJ, Brown IR (2001) Expression of mRNA encoding extracellular matrix glycoproteins SPARC and SC1 is temporally and spatially regulated in the developing cochlea of the rat inner ear. Hear Res 155:161-174

Osako S, Hilding DA (1971) Electron microscopic studies of capillary permeability in normal and Ames waltzer deaf mice. Acta Otolaryngol 71:365-376.

Probst FJ, Fridell RA, Raphael Y, Saunders TL, Wang A, Liang Y, Morell RJ, Touchman JW, Lyons RH, Noben-Trauth K, Friedman TB, Camper SA (1998) Correction of deafness in shaker-2 mice by an unconventional myosin in a BAC transgene. Science 280:1444-1447.

Rendtorff ND, Frödin M, Attié-Bitach T, Vekemans M, Tommerup N (2001) Identification and characterization of an inner ear-expressed human melanoma inhibitory activity $(M I A)$-like gene $(M I A L)$ with a frequent polymorphism that abolishes translation. Genomics 71:40-52.

Robertson NG, Lu L, Heller S, Merchant SN, Eavey RD, McKenna M, Nadol Jr JB, Miyamoto RT, Linthicum Jr FH, Lubianca Neto JF, Hudspeth AJ, Seidman CE, Morton CC, Seidman JG (1998) Mutations in a novel cochlear gene cause DFNA9, a human nonsyndromic deafness with vestibular dysf unction. Nat Genet 20:299-303.
Robertson NG, Heller S, Lin JS, Resendes BL, Weremowicz S, Denis CS, Bell AM, Hudspeth AJ, Morton CC (2000) A novel conserved cochlear gene. OTOR: identification, expression analysis, and chromosomal mapping. Genomics 66:242-248.

Sage C, Ventéo S, Jeromin A, Roder J, Dechesne CJ (2000) Distribution of frequenin in the mouse inner ear during development, comparison with other calcium-binding proteins and synaptophysin. Hear Res 150:70-82.

Sakaguchi N, Crouch JJ, Lytle C, Schulte BA (1998) Na-K-Cl cotransporter expression in the developing and senescent gerbil cochlea. Hear Res 118:114-122.

Schägger H, von Jagow G (1987) Tricine-sodium dodecyl sulfatepolyacrylamide gel electrophoresis for the separation of proteins in the range from 1 to $100 \mathrm{kDa}$. Anal Biochem 166:368-379.

Schwartzberg P, Colicelli J, Gordon ML, Goff SP (1984) Mutations in the gag gene of moloney murine leukemia virus: effects on production of virions and reverse transcriptase. J Virol 49:918-924.

Scott DA, Wang R, Kreman TM, Sheffield VC, Karniski LP (1999) The Pendred syndrome gene encodes a chloride-iodide transport protein. Nat Genet 21:440-443.

Self T, Sobe T, Copeland NG, Jenkins NA, Avraham KB, Steel KP (1999) Role of myosin VI in the differentiation of cochlear hair cells. Dev Biol 214:331-341.

Shnerson A, Lenoir M, Van de Water TR, Pujol R (1983) The pattern of sensorineural degeneration in the cochlea of the deaf shaker-1 mouse: ultrastructural observations. Dev Brain Res 9:305-315.

Sjöström B, Anniko M (1990) Morphologically specific vestibular hair cell degeneration in the jerker mutant mouse. Eur Arch Otorhinolaryngol 247:51-55.

Soto-Prior A, Lavigne-Rebillard M, Lenoir M, Ripoll C, Rebillard G, Vago P, Pujol R, Hamel CP (1997) Identification of preferentially expressed cochlear genes by systematic sequencing of a rat cochlea cDNA library. Mol Brain Res 47:1-10.

Spicer SS, Schulte BA (1991) Differentiation of inner ear fibrocytes according to their ion transport related activity. Hear Res 56:53-64.

Spicer SS, Schulte BA, Adams JC (1990) Immunolocalization of $\mathrm{Na}+, \mathrm{K}(+)$-ATPase and carbonic anhydrase in the gerbil's vestibular system. Hear Res 43:205-217.

Spicer SS, Gratton MA, Schulte BA (1997) Expression patterns of ion transport enzymes in spiral ligament fibrocytes change in relation to strial atrophy in the aged gerbil cochlea. Hear Res 111:93-102.

Spoendlin H, Brun JP (1973) Relation of structural damage to response time and intensity in acoustic trauma. Acta Otolaryngol 75:220-226.

Stankovic KM, Adams JC, Brown D (1995) Immunolocalization of aquaporin CHIP in the guinea pig inner ear. Am J Physiol 269:C14501456.

Street VA, McKee-Johnson JW, Fonseca RC, Tempel BL, Noben-Trauth $\mathrm{K}$ (1998) Mutations in a plasma membrane $\mathrm{Ca}^{2+}$-ATPase gene cause deafness in deafwaddler mice. Nat Genet 19:390-394.

Thomadakis G, Ramoshebi LN, Crooks J, Rueger DC, Ripamonti U (1999) Immunolocalization of bone morphogenetic protein-2 and -3 and osteogenic protein-1 during murine tooth root morphogenesis and in other craniofacial structures. Eur J Oral Sci 107:368-377.

Towbin H, Staehelin T, Gordon J (1979) Electrophoretic transfer of proteins from polyacrylamide gels to nitrocellulose sheets: procedure and some applications. Proc Natl Acad Sci USA 76:4350-4354.

Tsuprun V, Santi P (1999) Ultrastructure and immunohistochemical identification of the extracellular matrix of the chinchilla cochlea. Hear Res 129:35-49.

Vetter DE, Mann JR, Wangemann P, Liu J, McLaughlin KJ, Lesage F, Marcus DC, Lazdunski M, Heinemann SF, Barhanin J (1996) Inner ear defects induced by null mutation of the isk gene. Neuron 17:1251-1264.

Weinberger DG, Ten Cate WJ, Lautermann J, Baethmann M (1999) Localization of laminin isoforms in the guinea pig cochlea. Laryngoscope 109:2001-2004.

Wilcox ER, Fex J (1992) Construction of a cDNA library from microdissected guinea pig organ of Corti. Hear Res 62:124-126.

Xia AP, Ikeda K, Katori Y, Oshima T, Kikuchi T, Takasaka T (2000) Expression of connexin 31 in the developing mouse cochlea. NeuroReport 11:2449-2453.

Zheng L, Sekerkova G, Vranich K, Tilney LG, Mugnaini E, Bartles JR (2000) The deaf jerker mouse has a mutation in the gene encoding the espin actin-bundling proteins of hair cell stereocilia and lacks espins. Cell 102:3776-3785. 